\title{
Effect of Gratification, Utilitarian, and Trust Elements on the Use of Retail Mobile Banking App in Africa: A Comparative Study
}

\author{
Sunday Adewale Olaleye \\ Department of Marketing, Management and Intern. Business \\ University of Oulu Business School, \\ Oulu, Finland \\ sunday.olaleye@oulu.fi \\ Emmanuel Awuni Kolog \\ Dept. of Operations and Management Information System \\ University of Ghana Business School \\ Accra, Ghana \\ eakolog@ug.edu.gh
}

\author{
Richard Osei Agjei \\ School of Public Health \\ University of Central Nicaragua, \\ Nicaragua \\ richardagjei@outlook.com \\ Joseph Budu \\ Dept. of Information Systems and Innovation \\ Ghana Institute of Management and Public Administration, \\ Accra, Ghana \\ josbudu@gimpa.edu.gh
}

\begin{abstract}
Information and communication technology has ushered in an era where business organisations are striving to create value for their customers to ensure retention. Ubiquitous nature of mobile devices provides opportunity to run retail banking apps where many people can use at anytime and anywhere to engage in banking transactions. Using these apps, we investigate, comparatively, the effect of gratification, utilitarian and trust elements towards the use of retail mobile banking app. This study was grounded on Gratification and the Unified theory of acceptance and use of technology theories. Data was collected from participants from Ghana, Nigeria and South Africa. By analysing the data with SmartPLS, the results show a minor variation in the effect of Gratification, Utilitarian, and Trust elements on the use of retail mobile banking app in the selected countries in Africa. These findings suggest that technology innovation inclusive should be encouraged in the development of retail mobile banking app in order to improve on customer experience.
\end{abstract}

Keywords-Mobile banking, gratification, trust, utilitarian, Mobile app

\section{INTRODUCTION}

With 731 million SIM connections at the end of 2016, and a potential rise to 1 billion by 2020, Africa is the fastest growing mobile market [1]. Such statistics have attracted businesses on the continent to develop new mobile telephony-based services. For instance, retail banks extend their services using mobile banking apps. Naturally, mobile banking apps have been the subject of many research efforts which have focused on assessing their vulnerabilities and proposing threat detection and mitigation model [2], determining customer adoption factors [3], and identifying the extent to which bank websites disclose information about mobile banking [4]. These studies suggest two themes in mobile banking research including customer adoption factors [5] [6]; and evaluation of mobile banking services [7], [8] [9]. These studies are valuable in that, for instance, they show how habit, price value, and trust influence customers to adopt mobile banking services in Ghana [3].

Unfortunately, research about the factors affecting the use of mobile banking applications is scarce. Existing mobile banking studies have also focused on customers' continuance use intention [10], and benefits and the satisfaction derived from using mobile banking [11]. Overall, existing studies failed to hypothesize and test the factors that determine the actual use and continuous use of mobile banking applications. To fill this gap, the purpose of this paper is to determine how gratification (affective, cognitive and tension free), utilitarian (performance expectancy, social influence, facilitating conditions), and trust (trust and privacy) elements affect the use of retail mobile banking Apps and to determine the relationship between the use and continuous use of retail mobile banking.

In view of this objective, the rest of the paper is organized as follows: Section two presents the background of the study. The background encompasses the overview and role of retail mobile banking app in banking ecosystem. Research model and the hypothesis development are presented in Section three. This is followed by a description of the research methodology and the method of data analysis in Section four. Section five presents the results after the data analysis. Discussion of the findings and relevant implications of the findings are in Section Five. Conclusion and direction for future research are suggested in section Six.

\section{BACKGROUND}

The fast springing-up of banks and other financial institutions have created competitions that require an innovative approach to reach out to many customers. Thus, ICT has ushered in an era where business organisations strive to create value for their customers to ensure retention. Creating value for customers do not only enhance flexibilities in engaging business transactions, it helps businesses to survive. However, the survival rate of businesses largely hinges on its ICT innovational approaches. In attempt to stay relevant in the business ecosystem, financial institutions have integrated Information and communication technology (ICT) into their banking activities. Ubiquitous nature of mobile devices has heightened the flexibilities on reaching many customers thereby improving customer gratification. 
New technologies, such as mobile technology, are well recognized and practised by the industries as a promising and competitive innovation. Mobile banking apps, for instance, provide a way of meeting the demands of impatient customers. Banks are therefore being advised to build for the mobile experience because of a shift in consumers' platform preference [12]. Unsurprisingly, banks in Africa have been launching new mobile banking services e.g. Ghana Commercial Bank [13] and Standard Chartered Bank [14]. The Standard Chartered app, for instance, allows a customer to open an account after which a free debit card is delivered free of charge to the customer's destination within 48 hours. More interestingly, the banking industry is witnessing the rise of mobile-only banks, demonstrating how convenience drives the modern consumer [15]. These initiatives are in line with mobile banking transactions which are forecasted to double by 2022, whilst inperson branch banking may decline by $36 \%$ during the same period [16].

Despite this trend, consumers have major security concerns. Results of a recent survey of 3,100 adults suggest their strong distrust for internet privacy [17]. Such pessimism may be because of the suspicion of what financial technology companies do with consumer data [18]. Privacy is a big issue with mobile banking because consumers' lack of confidence in the security of their information holds them back from adopting [19]. Similarly, consumers have issues with the ease of use and hidden fees that could be associated with banking online [20]. Overall, consumers' perception of privacy can influence their perception of trust in mobile banking applications. Mistrust and/or unfavourable perception of privacy in the application could lead to a rejection of the service, which also means poor failed objectives and possible low return on investment to the bank. We, therefore, need to understand the extent to which these factors influence consumers' use of mobile banking applications in order to engender more trust and provide better privacy mechanisms.

\section{RESEARCH MODEL AND HYPOTHESIS DEVELOPMENT}

In this section, we provide a detailed overview of the hypothesis formulation and the research model shown in Fig. 1.

\section{A. Tension free and mobile banking app use}

Tension free refers to the potential for a technology to reduce a person's tension by providing a relaxing alternative and an escape from relatively stressful life issues [21]. Mobile banking may not be so entertaining, but a user could potentially use it to avoid vehicular traffic from home or office to the banking hall, and human traffic in the banking hall queues. Using a mobile banking app for a successful transaction may also generate some relaxation. Therefore, we hypothesise that:

H1. Tension free is positively related to mobile banking app use

\section{B. Affective and mobile banking app usage}

Affective is a type of that media which generates for their users or consumers [22]. Consumption of the media creates a form of enjoyment for the user. Consequently, we expect that the use of a retail mobile banking application would engender some enjoyment as a form of media. The user should experience enjoyment knowing that a task is being accomplished through the use of the mobile application. Hence, we hypothesise that:

$\mathrm{H} 2$. Affective is positively related to mobile banking app use

\section{Cognition and mobile banking app use}

Users' cognitive process is essentially the process of retrieving information [23]. Naturally, previous research has explored cognitive evaluations in the context of mobile shopping for fashion products [24]. The relationship suggests the use of cognition during the use of technology in general. Hence during the use of a mobile banking application, a user would retrieve some information e.g. username, password, and account balance. The ability for the application to enhance the users' information retrieval would affect whether they use the application or not. Hence, we hypothesise that:

\section{H3. Cognition is positively related to mobile banking app use}

\section{Social influence and cognition}

Social influence refers to the social interaction that affects a user's thought, feeling, attitude or behavior [25]. If social influence affects thoughts, then users' cognition is also affected. Consequently, there is a relationship between social influence and cognition. The presence of social influence around a mobile banking application user would influence her thoughts and cognition about the use of the application. Hence, we hypothesise that

\section{H4. Social influence is positively related to cognitive}

\section{E. Social influence and mobile banking app use}

Social influence refers to the social interaction that affects a user's thought, feeling, attitude or behavior [25]. In other words, a user's interaction with other peers and colleagues can affect what she thinks or feels about mobile banking application, and subsequently her attitude and behavior towards same. For instance, social influence was found to be an external factor in students' continued use of virtual desktop services [26]. Because social influence can make someone use a mobile banking application, we hypothesise that:

\section{H5. Social influence is positively related to mobile banking app use}

\section{F. Facilitating conditions and mobile banking app use}

Facilitating condition is the degree to which an individual believes that an available organizational and technical infrastructure supports the use of the system [27]. Triandis's [28] found facilitating condition encompass types of service and the degree of its influences on individuals use of the prospective technology. It is a functional combination of the degree of acceptance of the important innovations in information system $[29,30]$. Facilitating conditions are reflected as relevant aspects in noticing the acceptance behaviour of individuals towards the use of mobile banking app [39]. In view of this, we hypothesis that:

H6. Facilitating conditions is positively related to mobile banking app use 


\section{G. Performance expectancy and mobile banking app continuous use}

Performance expectancy is the degree to which an individual believes that a job performance will improve by using innovative technologies [31]. Venkatesh et al. [31] proposed two technological variables; performance expectancy and effort expectancy. Performance expectancy is one's perception that the use of mobile banking and continuous use will improve performance [32]. Thus, we propose the following hypothesis:

H7. Performance expectancy is positively related to mobile banking app continuous use

\section{H. Trust and mobile banking app continuous use}

The lack of trust is frequently cited as a reason for consumers unwillingness to use mobile banking apps [33]. Trust is the willingness of customers to be vulnerable to a trustee (mobile banking app) expecting that the trustee will fulfil its obligations [34]. Trust allows users to willingly become vulnerable after having taken the bank's characteristic embedded in its mobile banking app where its process is usually akin to trust in people. Therefore, we hypothesized that:

\section{H8. Trust is positively related to mobile banking app} continuous use

\section{Privacy and Trust}

Privacy can be considered as a construct that is either met or not, but it can also be seen as a measurable construct, where the value depends on the degree of trust of the trustor in the trustee protected against potential risk [35]. The amount of trust required is dependent on the sensitivity of the information and this is highly depended on the degree of privacy [35]. Once a consumer becomes aware that his location, identity and footprint privacy is not assured the level of trust in the use and continuous use of mobile banking will automatically decline. The most significant element to have success in continuous use of mobile banking app is to create trust with consumers by assuring privacy protection. Based on this, we hypothesis that:

H9. Privacy is positively related to trust

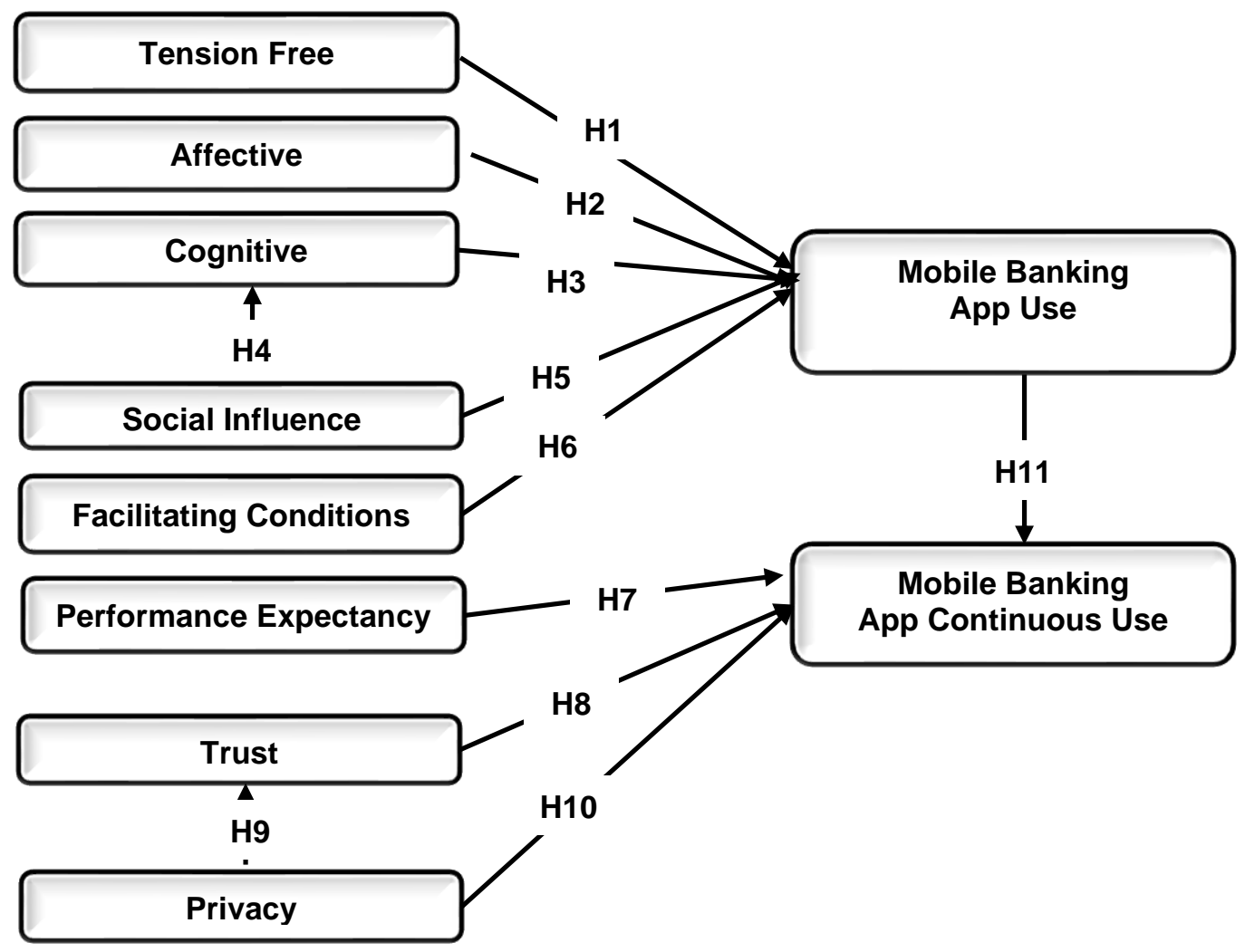

Fig. 1 Conceptual model of the research

\section{J. Privacy and mobile banking app continuous use}

As mobile banking app use business is proliferating because numerous studies about Appstore platform or apps development have been conducted. Mobile banking apps which are easy to use would attract consumers to use them and will continue to use them as long as consumers' privacy is guaranteed [36]. The significant and positive association between mobile banking app use and ease of use can trigger continuous use of mobile banking App as long as users' privacy is considered. This suggests that consumers' perception of the usefulness of apps sustains the continuous use provided their privacy is intact. Thus, what makes mobile banking app users continuously use a particular app is the initial assurance of privacy. 
H10. Privacy is positively related to mobile banking app continuous use

\section{K. Mobile banking app use and mobile banking app continuous use}

Research has revealed that the most significant element to have success by the use of technology is to create trust with users by assuring them the protection of privacy and security since mobile banking app users feel they lack control over the access that web merchants have to their personal information during the online navigation process [37]. Since mobile banking app users perform the transaction in an imaginary space, it suggests that trust in the use of mobile banking app will promote continuous use. Therefore, the use of mobile banking app becomes a guarantee for continuous use of mobile banking app. Considering the above arguments and findings in the recent literature, this hypothesis has been proposed:

H11. Mobile banking app use is positively related to mobile banking app continuous use

\section{Methodology}

The study developed a robust scale from the extant studies and utilised seven-point Likert scales from strongly disagree to strongly agree. Questions on variables of social influence and facilitating conditions were modified from the study of Venkatesh et al. [31] while the variables of tension-free from Smock, Ellison, Lampe and Wohn, [ 53] and affective from Ha, Kim, Libaque-Saenz, Chang, and Park [38] were modified to suit the mobile banking use variable. Besides, continuous use was adapted from Lu [39]. Trust and privacy were extracted from Flavián and Guinalíu [40]. The items of use and continuous use were modified from the study of Venkatesh and Goyal [41]. The study also included the demographics of gender and education (check Tables 1 to 3 for details).

The study employed a convenience sampling method and administered questionnaires in Ghana, Nigeria, and South Africa to banking mobile apps users. The group that attends to the questionnaires are customers that use mobile banking apps to carry out transactions within and across the banks. The study used $(n=168)$ responses from Ghana, $(n=245)$ responses from Nigeria and $(n=69)$ responses from South Africa making 482 responses altogether from three countries in Sub-Saharan Africa. The analysis of the data was quantitatively carried out. The study used SmartPLS 3.0 with variance structural equation modelling technique for data analysis because of enhanced interface and functionalities for multigroup data analysis $[42,43]$.

The measurement model was evaluated through the lens of assessing individual reliability and internal consistencies. The various items under each of the constructs were above the acceptable threshold of 0.70 . Additionally, the internal loadings help determine which of the items to be included in the model. While some of the items were rejected because they loaded poorly (lower than 0.5 ), the remaining items satisfied the accepted standard.

\section{RESULTS}

\section{A. Demographic information}

Tables 1 to 3 show the demography of gender and education for Ghana, Nigeria, and South Africa. Nigeria has the highest male (159), Ghana with the highest female (79) and South Africa with the highest education level (15). However, the highest of the participants with $\mathrm{PhD}$ degrees were from South Africa (15) while the lowest came from Ghana.

TABLE 1: Demographic information of the participants from Ghana $(n=168)$

\begin{tabular}{|c|c|c|c|}
\hline \multicolumn{2}{|c|}{ Demography } & Freq. & \% \\
\hline Gender & Male & 89 & 53 \\
\hline & Female & 79 & 47 \\
\hline Education & High School/Diploma & 61 & 36 \\
\hline & Bachelor's Degree & 86 & 51 \\
\hline & Master's Degree & 14 & 8 \\
\hline & PhD & 2 & 2 \\
\hline & No Formal Education & 5 & 3 \\
\hline
\end{tabular}

TABLE 2: Demographic information of the participants from Nigeria $(n=245)$

\begin{tabular}{|c|c|c|c|}
\hline \multicolumn{2}{|c|}{ Demography } & & \\
\hline Gender & Male & 159 & 65 \\
\hline & Female & 86 & 35 \\
\hline Education & High School/Diploma & 116 & 47 \\
\hline & Bachelor's Degree & 78 & 32 \\
\hline & Master's Degree & 39 & 16 \\
\hline & PhD & 7 & 3 \\
\hline & No Formal Education & 5 & 2 \\
\hline
\end{tabular}

TABLE 3: Demographic information of participants from South Africa $(n=69)$

\begin{tabular}{|c|c|c|c|}
\hline \multicolumn{2}{|c|}{ Demography } & Freq. & $\%$ \\
\hline Gender & Male & 53 & 77 \\
\hline & Female & 16 & 23 \\
\hline Education & High School/Diploma & 1 & 1 \\
\hline & Bachelor's Degree & 12 & 18 \\
\hline & Master's Degree & 40 & 58 \\
\hline & PhD & 15 & 22 \\
\hline & No Formal Education & 1 & 1 \\
\hline
\end{tabular}

\section{B. Mobile Banking Apps Multigroup Model Assessment}

To ascertain the discrepancy of mobile banking apps in SubSaharan Africa, the study conducted multigroup analysis with SmartPLS Bootstrapping. The comparison analysis reveals major and minor discrepancies while some latent variable relationship did not show any discrepancy. The perception of mobile banking apps users concerning tension free is a bit higher in South Africa than Ghana and Nigeria (-0.27/0.17/2.23). Affective perception of mobile banking apps users is significant only in South Africa while Nigeria and Ghana were insignificant $(0.23 / 0.17 / 0.11)$.

Cognitive perception of mobile banking apps was higher in Ghana than South Africa and Nigeria (0.38/0.26/0.27). Social influence as a predictor of cognitive is higher in Nigeria than Ghana and South Africa (0.67/0.59/0.43) while social influence relationship with mobile banking apps use is higher in Ghana than Nigeria and South Africa (0.23//0.21/0.05). Facilitating conditions influence on mobile banking apps use is higher in South Africa than the two other two countries and tally in Nigeria and Ghana $(0.73 / 0.41 / 0.31)$. 
Performance expectancy perception on mobile banking apps continuous use is higher in Nigeria than South Africa and Ghana $(0.26 / 0.39 / 0.14)$. Trust as a predictor of mobile banking apps continuous use is higher in Nigeria than South Africa and Ghana $(0.25 /-0.06 / 0.12)$. Privacy as a predictor of trust is higher in Nigeria than South Africa and Ghana (0.83/0.82/0.72) while privacy connection with mobile banking apps continuous use is higher in South Africa than Nigeria and Ghana and was insignificant across the three countries (-0.06/-0.05/0.05). Perception of mobile banking use as a predictor of mobile banking continuous use is slightly higher in Ghana than Nigeria and major discrepancy in comparison with South Africa (0.57/0.48/0.56). See Figure xx for details. H1, H3, H4, H6, H9 and $\mathrm{H} 11$ were accepted across the countries while H2, H5, H7, $\mathrm{H} 8$ were partially accepted and H10 were rejected across the three countries.

Concerning country model comparison, the variance (R2) explained in mobile banking apps cognitive is higher in Nigeria than Ghana and South Africa (44\%, 32\%, 17\%). Trust variance is higher in Nigeria than South Africa and Nigeria (69\%, 66\%, $51 \%$ ). Mobile banking apps use variance is higher in South Africa than Nigeria and Ghana $(87 \%, 62 \%, 42 \%)$ while mobile banking apps continuous use variance is higher in South Africa than Nigeria and Ghana $(89 \%, 71 \%, 56 \%)$. Table 4 gives details.

TABLE 4: Mobile banking apps comparison and hypotheses results

\begin{tabular}{|c|c|c|c|c|c|}
\hline \multicolumn{6}{|c|}{ T-TEST } \\
\hline Variable relationship & Ghana & Nigeria & South Africa & Discrepant & Remarks \\
\hline TF $->$ MBAU & $2.39(0.017)$ & $2.23(0.027)$ & $2.60(0.010)$ & Minor & $\mathrm{A} / \mathrm{A} / \mathrm{A}$ \\
\hline Affective -> MBAU & $1.09(0.276)$ & $1.52(0.128)$ & $2.40(0.017)$ & Minor/Yes & $\mathrm{R} / \mathrm{R} / \mathrm{A}$ \\
\hline Cognitive $->$ MBAU & $4.01(0.000)$ & $2.35(0.019)$ & $3.55(0.000)$ & Yes & $\mathrm{A} / \mathrm{A} / \mathrm{A}$ \\
\hline SI -> Cognitive & $8.38(0.000)$ & $14.41(0.000)$ & $3.82(0.000)$ & Yes & $\mathrm{A} / \mathrm{A} / \mathrm{A}$ \\
\hline SI $->$ MBAU & $2.58(0.010)$ & $2.09(0.037)$ & $0.89(0.376)$ & Minor/Yes & $\mathrm{A} / \mathrm{A} / \mathrm{R}$ \\
\hline FC -> MBAU & $4.91(0.000)$ & $4.91(0.000)$ & $9.02(0.000)$ & $\mathrm{No} / \mathrm{Yes}$ & $\mathrm{A} / \mathrm{A} / \mathrm{A}$ \\
\hline PE -> MBCU & $1.75(0.081)$ & $3.14(0.002)$ & $2.96(0.003)$ & Yes & $\mathrm{R} / \mathrm{A} / \mathrm{A}$ \\
\hline Trust -> MBCU & $1.47(0.142)$ & $2.21(0.028)$ & $0.81(0.418)$ & Yes & $\mathrm{R} / \mathrm{A} / \mathrm{R}$ \\
\hline Privacy $->$ Trust & $12.55(0.000)$ & $25.78(0.000)$ & $15.58(0.000)$ & Yes & $\mathrm{A} / \mathrm{A} / \mathrm{A}$ \\
\hline Privacy -> MBCU & $0.48(0.633)$ & $0.51(0.610)$ & $0.98(0.326)$ & Minor & $\mathrm{R} / \mathrm{R} / \mathrm{R}$ \\
\hline MBAU -> MBCU & $6.46(0.000)$ & $6.41(0.000)$ & $3.95(0.000)$ & Minor/Yes & $\mathrm{A} / \mathrm{A} / \mathrm{A}$ \\
\hline \multicolumn{6}{|l|}{ Quality criteria } \\
\hline Cognitive & $32 \%$ & $44 \%$ & $17 \%$ & & \\
\hline Trust & $51 \%$ & $69 \%$ & $66 \%$ & & \\
\hline MBAU & $42 \%$ & $62 \%$ & $87 \%$ & & \\
\hline MBCU & $56 \%$ & $71 \%$ & $89 \%$ & & \\
\hline
\end{tabular}

TF: Tension Free; SI: Social Influence; FC: Facilitating Conditions; MBAU: Mobile Banking Apps Use;

MBCU: Mobile Banking Apps Continuous Use

*Two-tailed hypotheses. Significant at $p<.01, .05$. A: Accepted, R: Rejected

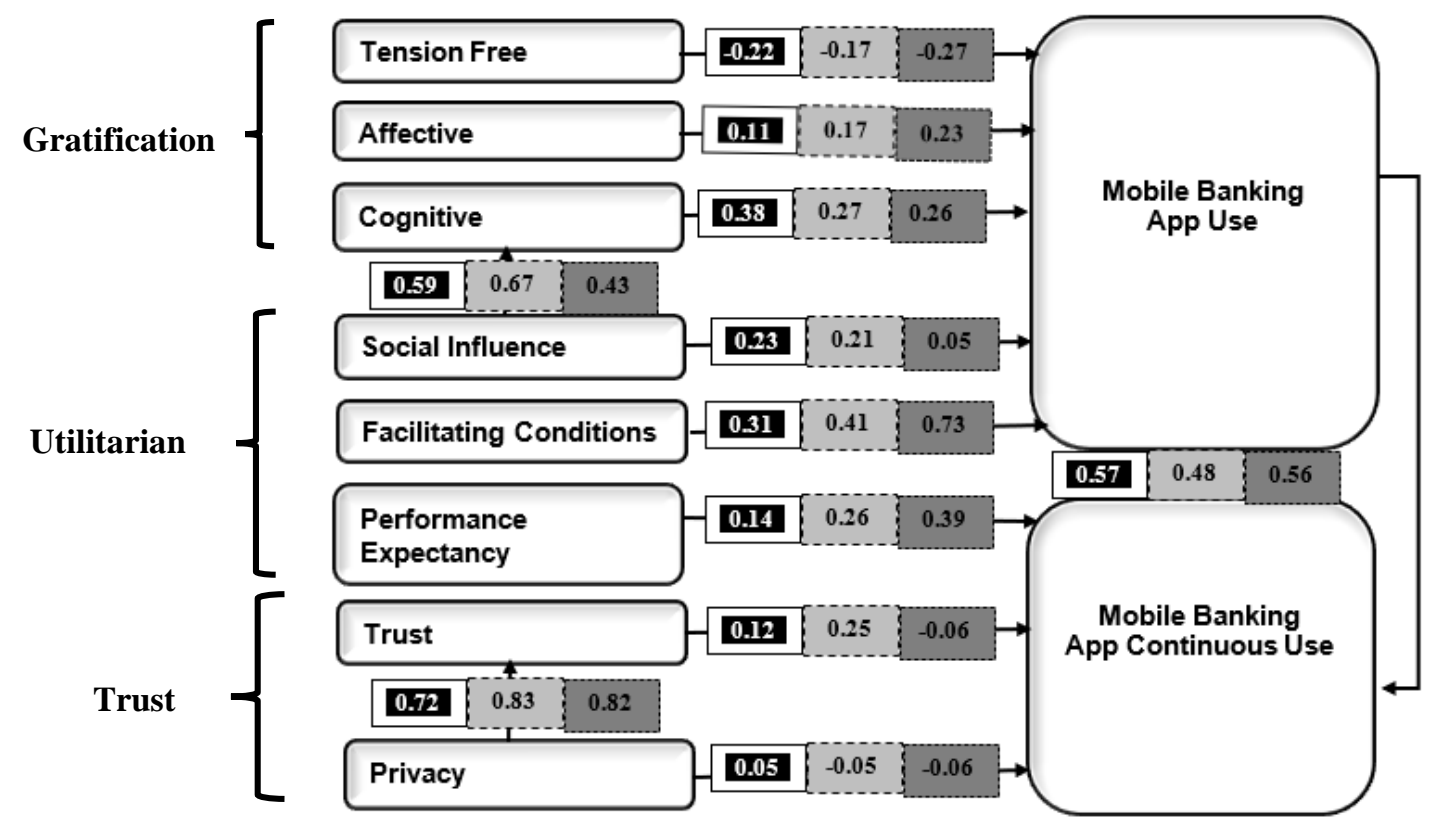

Fig. 2. Research model showing the various t-test values 


\section{DISCUSSION AND IMPLICATION}

The paper investigated the effect of gratification, utilitarian and trust elements towards the use of retail mobile banking apps, and further determined the relationship between the use and continuous use of retail mobile banking app in Africa. Under each of these elements were constructs formulated based on existing theories: UTAUT and Gratification theories. With these theories, eleven hypotheses were formulated to test the effect of gratification, utilitarian and trust elements on the use of retail mobile banking apps. We collected data, analysed and compared the findings of three African countries: Ghana, Nigeria and South Africa. The multigroup analysis of this study found minor, major and no discrepancies in the findings. As indicated in Tables 1 to 3, the findings of this study are eminent as it has both managerial and academic implications.

In terms of the user gratification; affective, cognitive and tension- free constructs towards the use of mobile banking app were investigated. This study shows a significance in cognitive perception of using mobile banking app in all the three countries under study. Although the level of significance varied slightly, the findings go to imply that customers' cognitive gratification level aligns with their sense of using mobile banking app in Africa. This finding is consistent with existing research which found cognitive gratification as a significant measure for using mobile banking apps [44]. In the same vein, the affective perception on the use of mobile app was only significant in South Africa. This implies that, in South Africa, users of Mobile apps place much emphasis on the content and information that the app provides. This goes to show that the functional features of retail mobile banking apps play a key role in user affective gratification. People would not be affectively gratified if Mobile apps do not provide relevant information for them, especially information on events, products, services and knowledge relating to security [45]. This finding is contrary to the situation in Ghana and Nigeria. In these countries, the study yielded cognitive insignificance towards the use of Mobile banking apps. This is to imply that users are affective on the functionalities of mobile apps. Additionally, this study has found tension-free as significant towards the use of mobile banking apps in all the three African countries. With this finding, customers/users are willing to use retail mobile banking apps under stress-free or voluntary environment. While aiming to use mobile apps for banking purposes, users expect to enjoy the use with easy and with no imposition of strict conditionalities. This is to suggest tension-free as a key element towards user gratification on using mobile banking app.

The utilitarian element was adopted from UTAUT theory. Thus, only three of the UTAUT's four main constructs were adopted: Social influence, facilitating condition and performance expectancy. These were adopted based on its widely used in technology adoption research [31, 46]. In this study, social influence was found to be a significant determiner towards the use of mobile banking app in Ghana and Nigeria. This finding goes to imply that users in Ghana and Nigeria are likely to be motivated in using mobile banking app if their close friends and associates encourage them to. For instance, many people use mobile banking app after it has been recommended by others, and this study finds a similar case in Ghana and Nigeria in terms of the use of mobile banking apps. This finding is contrary to the case of South Africa where the use of mobile banking app is not motivated by close pals and associates. Conversely to Ghana and Nigeria, and in line with the case of South Africa, Palau-Saumell et al. [50] unexpectedly found social influence as the least driver of intentions to use mobile baking apps. Furthermore, the relationship between social influence and cognition is supported in this work. This is to imply that social influence affects the thoughts of users as many believe that close associates can influence their decision. In effect, the presence of social influence around a mobile banking application user would influence their thoughts and cognition about the use of the application in all the selected countries under this study.

Facilitating condition is the belief that there is available technical infrastructure to support the use of a mobile banking app. This study has revealed, in all the three countries, that people would be motivated to use mobile banking app if there exist supporting tools such as mobile phones and internet availability. This can also be attributed to the cost of the internet infrastructure. People may decline on using mobile app because of the cost associated with internet usage. Although research has predicted an overwhelming impact of the internet on economic activities in Africa [51], there is also a growing concern of the cost of the internet [52]. Performance expectancy yielded insignificant towards the use of mobile banking app in Ghana. This implies that users are adamant on the performance (speed) of the technology tool that supports the use of mobile app. People would rather make use of their limited resources to access mobile banking app. This finding is not the case in the context of South Africa and Nigeria. In these two countries, users are motivated to use mobile banking apps when there exist available tools, such as mobile phones with smart features, to enhance flexibility.

The trust element, especially in the African context, has been a subject of concern to users of mobile banking apps. Trust in mobile banking use is dependent on consumers' perceptions of the capabilities of the technology [49]. Users are being defrauded with the least mistake committed by either themselves or by providers of mobile apps. Except for Nigeria, in this study, we found no relation between the continuous use of mobile banking app and trust levels of users in Ghana and South Africa. This is to imply that Nigerians would continuously use mobile banking app provided there are no trust issues with the mobile banking app. Conversely, users who are found being disappointed (trust) in using mobile banking apps will decline to use mobile banking app continuously. These disappointments, in most cases, is attributed to the functional and security issues of mobile banking app. Providers of mobile banking app sometimes shift blames to users in the case where they are scammed through the banking app.

Users value their privacy and the protection of their personal data. They value some control over who knows what about them. Therefore, privacy is one feature of banking app that require maximum attention due to its sensitive nature. Compromising privacy on mobile banking app demotivate people to use or lose trust. However, this present study has found no relation between continuous use of mobile banking apps and privacy for all the three African countries. Through mobile banking app, illegal invasion of privacy will see people 
declining to continuously use the app. For instance, one can decide to stop using mobile banking app not because his privacy has illegally been invaded. We further investigated the relationship between the use and continuous use of mobile banking apps. We found that once Mobile banking app is accepted for use; users will continue to use the app for all the three African countries.

\section{A. Theoritical and Managerial implications}

The findings of this study have some interesting implication to theory and for future studies. This study adopted and integrated two different theories: Gratification and UTAUT theories. From analysing previous works, no research has combined these two theories to study the comparative use and continuous use of mobile banking app in Africa. This is vital for academic work as the study has found interesting results relevant for practice. Through the data analysis with structural equation modeling, the study unravelled the effect of gratification, utilitarian and trust elements on the use of mobile banking app in Africa. To add is that, the comparative analysis has generally indicated minor variations in gratification, trust and utilitarian elements towards the use of mobile banking app in the African countries.

Given that several mobile banking apps have been developed for users, its acceptance in terms of user gratification and trust is eminent for user retention. This study has shown, in Ghana, Nigeria and South Africa, that the use and continuous use of mobile banking app is related to certain factors such as tension free, affective cognitive perception among others. With these findings, management of retail banking in Africa will be able to develop policies to motivate customer gratification, utilitarian and trust towards the use and continuous use of mobile banking app in Africa.

Additionally, Mobile banking app developers can base on these findings to engineer innovation inclusiveness, thereby enhancing user gratification and trust in using Mobile banking apps. Technology inclusive innovation (TII) has the potential to be a socially responsible endeavour [47]. TII motivates users of technology to be part of design and creative process with the aim of improving user experience [48]. In a related finding, retailers of mobile banking app are encouraged to "reposition their mobile app as a multitasking app of an information database for online e-shopping, gamification for rewards and video curation for socialization" $[48,54]$.

\section{B. Limitation and future research direction}

Three different Anglophone countries from Africa were involved in the study: two from West Africa (Ghana and Nigeria) and the other one from Southern African (South Africa). Since the study is grounded on a comparative study approach, the findings from the respective countries were compared and reported in Section 4. This makes the generalization of the results difficult to encompass the Francophone countries in Africa. Given the variation in these languages, it is expected that the development approach of retail mobile banking apps will differ. In this regard, we propose a future direction of research that considers the Francophone countries in Africa.
Additionally, the retail mobile banking app was generally considered. This, in effect, makes it difficult to narrow the results to a specific retail mobile banking app. Nevertheless, we maintain the relevance of this findings as a base to assess specific retail mobile banking app. We propose a future work that will consider specific retail mobile banking App.

Although, Gender and Age of the participants were collected and reported as descriptive findings, they were not used as moderating factors for the various adopted constructs in this research. Gender and age are reported as significant moderating elements to determine the adoption [31] and gratification [38] of using technology. We, therefore, propose a future research to consider gender and age as moderating factors in this line of research.

\section{CONCLUSION}

Unlike cooperate banking, retail banking deals directly with retail customers which bring in customer deposits that largely enable banks to make loans to their retail and business customers. Mobile banking apps have been deployed widely by retails bankers to bridge the gap, in terms of banking transactions, with their customers. In view of this, Customer gratification, utilitarian and trust are important elements for customer retention towards the use of retail mobile banking apps in Africa. This paper investigated these elements in the context of three African countries. The findings from the respective countries, as Gratification and UTAUT theories were adopted, were compared. With the use of structural equation modelling, the multigroup analysis of this study found minor, major and no discrepancies in the findings. This paper has both theoretical and managerial implication regarding the use and continuous use of mobile banking app in Africa. We, by the findings of this paper, propose a rigorous technology innovation inclusiveness towards the development of mobile banking app in Africa.

\section{REFERENCES}

[1] Africanews, "Over half a billion mobile subscribers in Africa by 2020 [Hi-Tech]," Africa News website, 2019.

[2] S. Bojjagani and V. N. Sastry, "VAPTAi: A Threat Model for Vulnerability Assessment and Penetration Testing of Android and iOS Mobile Banking Apps," in 2017 IEEE 3rd International Conference on Collaboration and Internet Computing, 2017, pp. 77-86.

[3] K. O. Kwateng, K. A. O. Atiemo, and C. Appiah, "Acceptance and use of mobile banking : an application of UTAUT2," J. Enterp. Inf. Manag., vol. 32, no. 1, pp. 118-151, 2019.

[4] F. F. O. Malaquias and Y. Hwang, "An empirical investigation on disclosure about mobile banking on bank websites," Online Inf. Rev., vol. 42, no. 5, pp. 615-629, 2018.

[5] T. Zhang, C. Lu, and M. Kizildag, "Banking ' on-the-go': examining consumers' adoption of mobile banking services," Int. J. Qual. Serv. Sci., vol. 10, no. 3, pp. 279-295, 2018.

[6] D. Chawla and H. Joshi, "Consumer perspectives about mobile banking adoption in India - a cluster analysis," Int. J. Bank Mark., vol. 35, no. 4, pp. 616-636, 2017.

[7] H. Komulainen and S. Saraniemi, "Customer centricity in mobile banking : a customer experience perspective," Int. J. Bank Mark., 2019.

[8] M. Jun and S. Palacios, "Examining the key dimensions of mobile banking service quality: an exploratory study," Int. J. Bank Mark., vol. 34, no. 3, pp. 307-326, 2016.

[9] C. P. Lee and J. P. Shim, "An empirical study on user satisfaction with mobile business applications use and hedonism," J. Inf. Technol. Theory Appl., vol. 8, no. 3, pp. 57-74, 2006. 
[10] R. R. Kumar, D. Israel, and G. Malik, "Explaining customer' s continuance intention to use mobile banking apps with an integrative perspective of ECT and Self-determination theory," Pacific Asia J. Assoc. Inf. Syst., vol. 10, no. 2, pp. 79-111, 2018.

[11] C. H. Sampaio, W. J. Ladeira, and F. O. Santini, "Apps for mobile banking and customer satisfaction: a cross-cultural study," Int. J. Bank Mark., vol. 35, no. 7, pp. 1133-1153, 2017.

[12] J. Marous, "Banking Providers Must Think Mobile-First in Today's Omni-Channel World," Financial Brand website, 2018. .

[13] GCB, "GCB Bank Launches Complete Mobile Banking Service," GCB website, 2019. [Online]. Available: https://www.gcbbank.com.gh/newsfrom-gcb/306-gcb-bank-launches-complete-mobile-bankingservice.html. [Accessed: 06-May-2019].

[14] E. Bruce, "Stanchart launches full digital bank on mobile - Aims at deepening digital payments in Ghana," Daily Graphic website, 2019.

[15] J. Pinder, "New technologies are changing mobile banking," Fintech News website, 2019.

[16] Financial Brand, "Consumers Expect Everything On Demand, But Banks Are Slow To Respond," Financial Brand website, 2018.

[17] Financial Brand, "Consumers Crave More Mobile Banking Features Despite Security Concerns," Financial Brand website, 2018. [Online]. Available: https://thefinancialbrand.com/74044/mobile-bankingfeatures-digital-security/. [Accessed: 06-May-2019].

[18] Financial Brand, "Consumers' Data Privacy Fears May Hurt Fintechs, Help Banks," Financial Brand website, 2018. .

[19] D. Weis, "With use surging, what comes next for mobile banking?," Mobile Payments Today website, 2018.

[20] J. Valdivia, "What the Research Says About Trust and Friction in Mobile Banking," Jumio website, 2018.

[21] A. D. Smock, N. B. Ellison, C. Lampe, and D. Y. Wohn, "Facebook as a toolkit: A uses and gratification approach to unbundling feature use," Comput. Human Behav., vol. 27, pp. 2322-2329, 2011.

[22] M. Sjoblom, M. Torhonen, J. Hamari, and J. Macey, "Content structure is king: an empirical study on gratifications, game genres and content type on Twitch," Comput. Human Behav., vol. 73, pp. 161-171, 2017.

[23] O. Ruixiang, H. Yao, P. Feng, and P. Hui, "Research on information retrieval model under scarcity theory and user cognition," Comput. Electr. Eng., vol. 76, pp. 353-363, 2019.

[24] E. Ko, E. Y. Kim, and E. K. Lee, "Modeling consumer adoption of mobile shopping for fashion products in Korea," Psychol. Mark., vol. 26, no. 669-687, 2009.

[25] Y. M. Huang and C. H. Liu, 'Supporting students' brainstorming using an augmented social network service and exploring their intention to use it," Int. J. Technol. Eng. Educ., vol. 9, no. 2, pp. 9-22, 2012.

[26] Y. M. Huang, "Examining students' continued use of desktop services: Perspectives from $\mathrm{T}$ expectation-confirmation and social influence," Comput. Human Behav., vol. 96, pp. 23-31, 2019.

[27] A. A. N. Mostafa \& B. Eneizan. Factors Affecting Acceptance of Mobile Banking in Developing Countries. International Journal of Academic Research in Business and Social Sciences, 8(1), 340-351, 2018.

[28] H.C. Triandis. Values, Attitudes, and Interpersonal Behavior. Nebraska Symposium on Motivation, University of Nebraska Press, Lincoln., 1980.

[29] J. Graham \& S. Hanton \& D. Connaughton. What Is This Thing Called Mental Toughness? An Investigation of Elite Sport Performers. Journal of Applied Sport Psychology 14. 205-218, 2002.

[30] D. Lu, P. Mausel, E. Brondízio \& E. Moran. Change detection techniques, International Journal of Remote Sensing, 25:12, 2365-2401, 2004.

[31] V. Venkatesh, M.G. Morris, G.B. Davis \& F.D. Davis. User acceptance of information technology: Toward a unified view. MIS Quarterly, 425478, 2003.

[32] M. Jambulingam. Behavioural Intention to Adopt Mobile Technology among Tertiary Students. World Applied Sciences Journal 22 (9): 12621271, 2013

[33] H-F. Lin . An empirical investigation of mobile banking adoption: The effect of innovation attributes and knowledge-based trust. Int $\mathrm{J}$. Information Management 31(3): 252-260, 2011.
[34] S. Yousafzai \& J. Pallister \& G. Foxall. Multidimensional role of trust in Internet banking adoption. Service Industries Journal - SERV IND J. 29. 591-605, 2009.

[35] A. Arabsorkhi \& H. M Sayad \& R. Ghorbanloo. A Conceptual Trust Model for the Internet of Things Interactions,In proceedings of 2016 symposium on Telecomunications. $89-93$.

[36] J.J. Hew, V-H. Lee, K-B. Ooi, J. Wei,"What catalyses mobile apps usage intention: An empirical analysis", Industrial Management \& Data Systems, Vol. 115 Iss 72015

[37] D. Hoffman, T. Novak \& A.M Peralta. Building Consumer Trust Online. Commun. ACM. 42. 80-85.1999.

[38] Ha, Y. W., Kim, J., Libaque- Saenz, C. F., Chang, Y., \& Park, M. C. Use and gratifications of mobile SNSs: Facebook and KakaoTalk in Korea. Telematics and Informatics, 32(3), 425-438, 2015.

[39] J. Lu. Are personal innovativeness and social influence critical to continue with mobile commerce?. Internet Research, 24(2), 134-159. 2014 Young, The Technical Writer's Handbook. Mill Valley, CA: University Science,

[40] C. Flavián, \& M. Guinalíu. Consumer trust, perceived security and privacy policy: Three basic elements of loyalty to a web site. Industrial Management \& Data Systems, 106(5), 601-620, 2006.

[41] V. Venkatesh \& S. Goyal. Expectation disconfirmation and technology adoption: Polynomial modeling and response surface analysis. MIS Quarterly, 281-303, 2010.

[42] J.F. Hair, C. M. Ringle, M., \& Sarstedt, M. PLS-SEM: Indeed a silver bullet. Journal of Marketing Theory and Practice, 19(2), 139-151, 2011.

[43] S.M. Almahamid, A.F. Tweiqat \& M.S. Almanaseer. University website quality characteristics and success: Lecturers' perspective. International Journal of Business Information Systems, 22(1), 41-61, 2016.

[44] A.V. Hausman, \& J.S. Siekpe. The effect of web interface features on consumer online purchase intentions. J. Bus. Res. 62 (1), 5-13, 2009.

[45] S. Nambisan \& R.A. Baron. Interactions in virtual customer environments: implications for product support and customer relationship management. J. Interact. Marketing 21 (2), 42-62, 2007.

[46] E. A. Kolog, E. Sutinen, M. Vanhalakka-Ruoho, J. Suhonen, \& E. Anohah. "Using unified theory of acceptance and use of technology model to predict students' behavioral intention to adopt and use ecounseling in Ghana". International Journal of Modern Education and Computer Science, 7(11), 1-11, 2015.

[47] E. Fisher." Responsible Innovation in a Post-Truth Moment". Journal of Responsible Innovation, 4(1): 1-4, 2017.

[48] S. A. Olaleye, I. T. Sanusi , B. Adepoju. "Actual Use and Continuous Use of Retail Mobile App: A Model Comparison Perspective" Advances in Science, Technology and Engineering Systems Journal Vol. 3, No. 6, 151158, 2018.

[49] B. M. Muir, \& N. Moray. Trust in automation: II. Experimental studies of trust and human intervention in a process control simulation. Ergonomics, 39(3), 429-460, 1996.

[50] R. Palau-Saumell, S. Forgas-Coll, J. Sánchez-García, E and Robres. eUser Acceptance of Mobile Apps for Restaurants: An Expanded and Extended UTAUT-2. Sustainability, 11, 2019. 1210; doi:10.3390/su11041210.

[51] L. ilver \& C. Johnson. "Internet Connectivity Seen as Having Positive Impact on Life in Sub-Saharan Africa but digital divide persist" 2018. Available on: https://pewrsr.ch/2He77Ra.

[52] Y. Kazeem. Having more rival mobile networks in a country often means cheaper internet for Africans" 2014. Available: https://qz.com/africa/1390318/africa-has-the-most-expensive-internetin-the-world/

[53] Smock, A. D., Ellison, N. B., Lampe, C., \& Wohn, D. Y. (2011). Facebook as a toolkit: A uses and gratification approach to unbundling feature use. Computers in Human Behavior, 27(6), 2322-2329.

[54] A. Dandison, C Ukpabi, H. Karjaluoto, S. A. Olaleye and S. M. Abass. Factors influencing mobile banking continuous use in Sub-Sahara Africa A study of mobile banking users in Nigeria: In book: Marketing and Mobile Financial Services: A Global Perspective on Digital Banking Consumer Behaviour. Routledge, 2018. 